\title{
Reaction Zone Imaging in a Dual-Mode Scramjet Combustor Using CH-PLIF
}

\author{
Daniel J. Micka* and James F. Driscoll ${ }^{\dagger}$ \\ University of Michigan, Ann Arbor, MI, 48109, USA
}

\begin{abstract}
Planar laser-induced fluorescence (PLIF) of the $\mathrm{CH}$ radical was used to image the reaction zone in a laboratory scale dual-mode ramjet/scramjet combustor. $\mathrm{CH}$ is well suited to be a reaction zone marker in this high speed flowfield due to its very short lifetime. The combustor consisted of a single, sonic, transverse fuel jet upstream of a wall cavity pilot flame. A mixture of $50 \%$ ethylene and $50 \%$ hydrogen by volume was used for fuel. Ramjet mode (thermally choked) combustion was studied at air stagnation temperatures of $1270 \mathrm{~K}$ and $1470 K$, which lead to two different reaction zone structures (cavity stabilized and fueljet-wake stabilized). The flame luminosity caused significant interference with the PLIF signal over the collection wavelengths of $420-440 \mathrm{~nm}$. A two camera technique was used to reduce the flame luminosity contribution to the signal. Instantaneous PLIF images show that the reaction zone is generally confined to relatively thin $(<3.3 \mathrm{~mm})$ layers. The $\mathbf{C H}$ layers are often quite shredded and discontinuous, particularly for the high temperature case. The ensemble averaged $\mathrm{CH}$ is distributed through a large area of the test section and is similar to the average flame luminosity.
\end{abstract}

\section{Nomenclature}

$H \quad$ test section height in constant area section

$\dot{m}_{\text {cavfuel }} \quad$ mass flow rate of cavity pilot fuel

$\dot{m}_{\text {totalfuel }} \quad$ mass flow rate of total fuel (includes cavity and main fuel)

$\phi \quad$ overall equivalence ratio $\left(\dot{m}_{\text {totalfuel }} /\right.$ stoichiometric $\left.\dot{m}_{\text {totalfuel }}\right)$

$P_{w} \quad$ wall static pressure

$P_{0, i} \quad$ air stagnation pressure upstream of the nozzle

$T_{0} \quad$ vitiated air stagnation temperature

$\mathrm{X}_{\mathrm{H}_{2} \mathrm{O}} \quad$ mole fraction of $\mathrm{H}_{2} \mathrm{O}$ in vitiator products

$\mathrm{X}_{\mathrm{O}_{2}} \quad$ mole fraction of $\mathrm{O}_{2}$ in vitiator products

$x \quad$ axial location in test section measured from cavity leading edge

\section{Introduction}

Dual-mode scramjet engines have the potential to provide air breathing propulsion at high flight Mach numbers. Wall fuel jet injection with a cavity flameholder is a desirable configuration for a dual-mode scramjet combustor due to the low pressure losses and cooling requirements. ${ }^{1-3}$ The cavity recirculation zone provides a long residence time for the fuel and air to mix and burn. The cavity flame provides a source of heat and radicals to ignite and stabilize combustion in the main flow. The main fuel injection may be normal to the air flow to achieve maximum penetration or it may be angled to recover some of the jet momentum. Previous studies have focused on combustors with such features, ${ }^{1,2,4-12}$ but the combustion stabilization mechanism and reaction zone structure are still not well understood.

Combustion stabilization is a significant challenge in dual-mode combustors due to the high velocities involved. After ignition at moderate flight Mach numbers, the incoming air temperature is insufficient to

\footnotetext{
*Graduate Student, Department of Aerospace Engineering, AIAA Member

${ }^{\dagger}$ Professor, Department of Aerospace Engineering, AIAA Fellow
} 
provide consistent auto-ignition and the combustion must be stabilized as a flame. In this flame regime, there must exist a location of favorable equivalence ratio, temperature, pressure, and velocity where the base of the reaction zone can stabilize and serve as a source of heat and radicals to the remaining fuelair mixture. ${ }^{1}$ Conversely, at very high flight Mach numbers, the incoming air temperature is sufficiently large that the auto-ignition delay time becomes negligible. In this auto-ignition regime, the combustion stabilization problem reduces to a mixing problem. At intermediate flight Mach numbers, both auto-ignition and flame properties are expected to be important. In a practical dual-mode combustor, the combustion must be stabilized over a wide range of conditions including ram-to-scram mode transition. Through these different regimes, the combustion stabilization location and mechanism may change.

Ramjet mode (thermally choked) combustion in a laboratory dual-mode combustor consisting of a transverse fuel jet upstream of a wall cavity pilot flame has been previously studied at the University of Michigan. ${ }^{13}$ Flame luminosity measurements revealed two distinct flame stabilization modes which are shown in Fig. 1 . At lower air stagnation temperatures $\left(T_{0} \lesssim 1270 \mathrm{~K}\right.$ for a blend of $50 \%$ ethylene, $50 \%$ hydrogen fuel $)$, the combustion is cavity stabilized. At high $T_{0}(\gtrsim 1470)$ the combustion is jet-wake stabilized. For intermediate $T_{0}$, the combustion oscillates between these two modes. The current study investigates the structure of the reaction zone for both these flame stabilization modes using CH-PLIF.

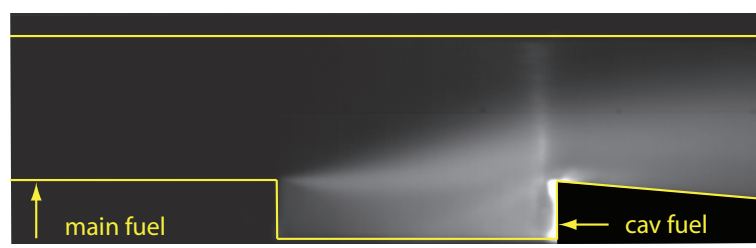

(a) Cavity stabilized combustion mode, $T_{0}=1260 \mathrm{~K}$.

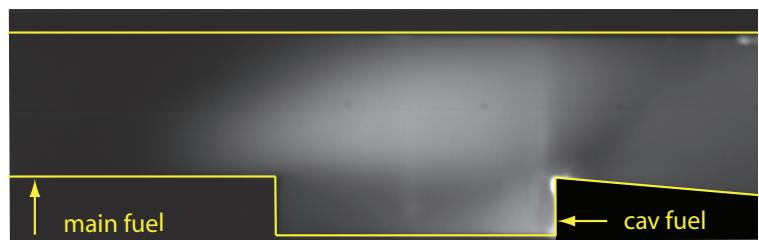

(b) Jet-wake stabilized combustion mode, $T_{0}=1490 \mathrm{~K}$.

Figure 1. Average flame luminosity images.

Visualization of $\mathrm{CH}$ in flames is useful because $\mathrm{CH}$ exists only in the localized layer of fuel consumption as originally shown by Porter et al. ${ }^{14}$ Regions of $\mathrm{OH}$, which have been previously imaged in scramjet combustors, ${ }^{3,5,6,15-17}$ are thickened due to slower recombination reactions. The thickening is particularly pronounced in high speed flows where premixing occurs before combustion. In scramjet combustors then, $\mathrm{OH}$ often exists in the hot products and thus is not a good marker of the reaction zone. ${ }^{5}$ Rasmussen $^{18}$ used PLIF to image $\mathrm{OH}$ and $\mathrm{CH}$ in a wall cavity flame with a supersonic freestream. He found the $\mathrm{CH}$ was confined to relatively thin layers while the $\mathrm{OH}$ was spread through a large volume of the cavity. No imaging of $\mathrm{CH}$ has been previously reported for scramjet combustors with main flow combustion.

\section{Experimental Setup}

\section{A. Combustor and Test Conditions}

Experiments were performed in the supersonic combustion facility at the University of Michigan. The test section is made of stainless steel and is shown in Figure 2. A two dimensional Mach 2.2 nozzle is followed by a constant area isolator with a cross section of $25.4 \mathrm{~mm}$ by $38.1 \mathrm{~mm}$. This constant area section extends 402 $\mathrm{mm}$ up to the leading edge of a rectangular cavity which is $50.8 \mathrm{~mm}$ long, $12.7 \mathrm{~mm}$ deep, and spans the width of the test section. At the rear edge of the cavity begins a $349 \mathrm{~mm}$ long 4 degree diverging section which dumps into a $152 \mathrm{~mm}$ diameter exhaust. Room temperature gaseous fuel was injected sonically through a single $2.49 \mathrm{~mm}$ diameter port located on the test section centerline $44.5 \mathrm{~mm}$ upstream of the cavity leading edge. Pilot fuel was directly injected into the cavity through 3 spanwise $1.19 \mathrm{~mm}$ diameter ports in the cavity rear wall. A spark plug in the cavity floor was used to ignite the cavity pilot flame and was the only ignition aid used. Fused silica windows $305 \mathrm{~mm}$ in length allowed imaging of the reaction zone.

The fuel consisted of $50 \%$ ethylene and $50 \%$ hydrogen by volume. Carbon content in the fuel was necessary for $\mathrm{CH}$ to be present in the reaction zone. The addition of hydrogen was necessary to achieve the desired flame stabilization modes for the values of $T_{0}$ available. ${ }^{13}$ The run conditions for the two cases tested are given in Table 1. An electric heater and hydrogen fueled vitiator were used to achieve the air stagnation temperatures of up to $1470 \mathrm{~K}$. Make-up oxygen was added to maintain a $0.21 \mathrm{O} 2$ mole fraction $\left(X_{\mathrm{H}_{2} \mathrm{O}}\right)$ in 


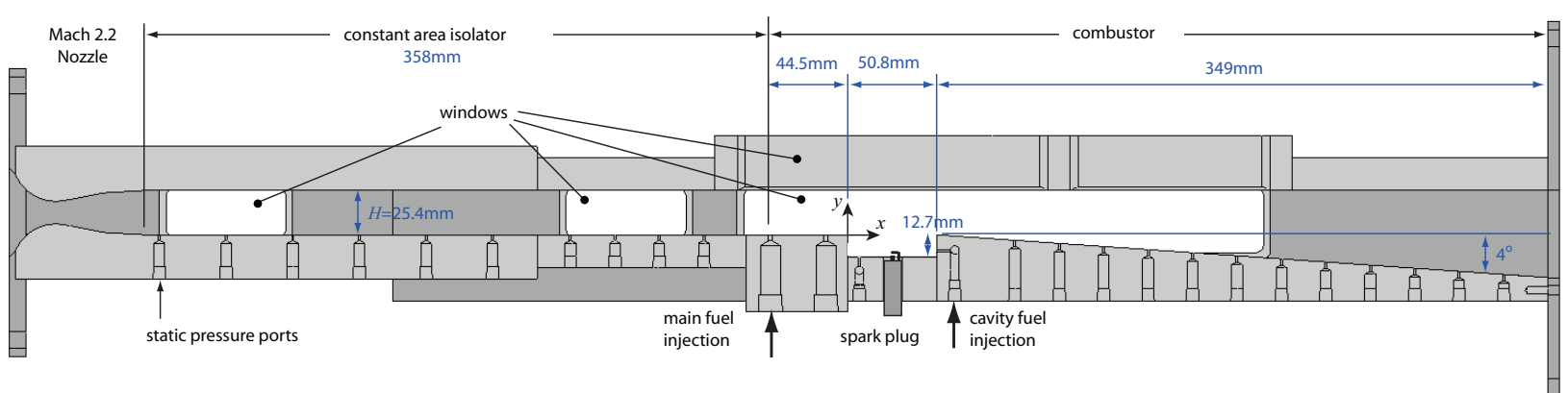

Figure 2. Test section with dimensions.

the vitiator products. The air temperatures were chosen such that for case 1 the combustion would be in the cavity stabilized mode greater than $90 \%$ of the time and for case 2 it would be in the jet-wake stabilized mode greater than $90 \%$ of the time. ${ }^{13}$ Both case 1 and 2 result in ramjet mode combustion. The average pressure in the test section for each case is shown in Fig. 3. The isolator exit Mach number is estimated to be 0.82 for case 1 and 0.70 for case 2 . This number is calculated from the last wall pressure measurement in the isolator at $(x / H)=-3.25$ and using the $1-\mathrm{D}$ method given by Curran et al. ${ }^{19}$

\begin{tabular}{ccc}
\hline Parameter & $\begin{array}{c}\text { Case } 1 \\
\text { cavity stabilized }\end{array}$ & $\begin{array}{c}\text { Case } 2 \\
\text { jet-wake stabilized }\end{array}$ \\
\hline \hline$P_{0, i}$ & $590 \mathrm{kPa}$ & $590 \mathrm{kPa}$ \\
$T_{0}$ & $1270 \mathrm{~K}$ & $1470 \mathrm{~K}$ \\
$\phi$ & 0.42 & 0.42 \\
$\dot{m}_{\text {cavfuel }} / \dot{m}_{\text {totalfuel }}$ & 0.05 & 0.05 \\
$X_{\mathrm{H}_{2} \mathrm{O}}$ & 0.17 & 0.24 \\
$X_{\mathrm{O}_{2}}$ & 0.21 & 0.21 \\
\hline
\end{tabular}

Table 1. Test conditions

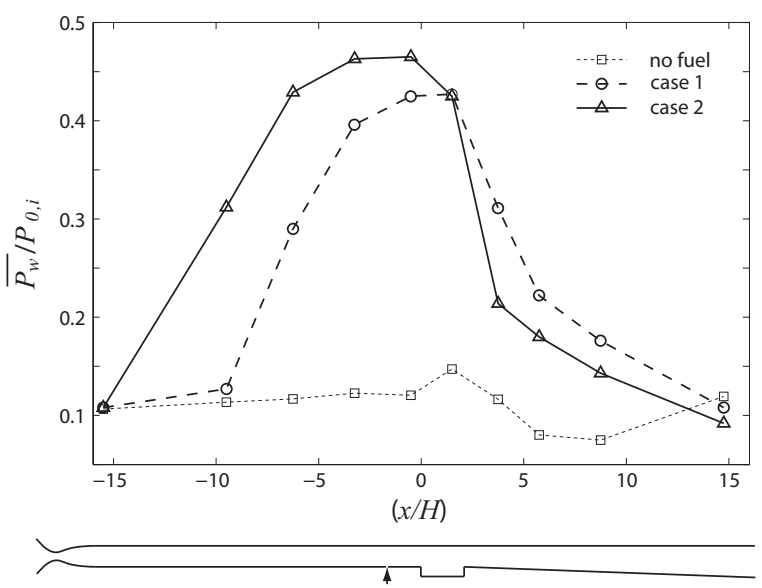

Figure 3. Average combustor wall pressure profiles for case 1 and 2 .

The run times were limited in order to prevent thermal damage to the uncooled combustor. All the flow control and data acquisition equipment was controlled by a Labview program. For each run, the air was first heated to $450 \mathrm{~K}$ by the electric heater. The vitiator oxygen flow was then started, followed two seconds later by the spark ignited vitiator fuel. Four seconds after vitiator ignition, the cavity fuel and cavity spark were turned on. One second later, the main fuel injection began. The main fuel flow was maintained for three

\section{3 of 12}


seconds before all flow streams except the main air were terminated.

The air stagnation temperature was measured by a K-type thermocouple in the settling chamber just upstream of the nozzle. The temperature generally increased by approximately $60 \mathrm{~K}$ during the 3 seconds the main fuel was on during each run. The average temperature measured during this time is reported as the nominal value of $T_{0}$. The initial air stagnation pressure $\left(P_{0, i}\right)$ was also measured in the settling chamber. The wall static pressure $\left(P_{w}\right)$ was recorded at $40 \mathrm{~Hz}$ at eight locations in the combustor and isolator. The measured wall locations could be varied between runs.

\section{B. PLIF System}

\section{Basic Arrangement}

The CH PLIF system used in the study is based on the method outlined by Garland and Crosley ${ }^{20}$ and demonstrated by Carter et al. ${ }^{21}$ The $Q_{1}(7.5)$ transition of the $B^{2} \Sigma-X^{2} \Pi(0,0)$ band of the $\mathrm{CH}$ molecule was excited by pumping at $390.30 \mathrm{~nm}$. The resulting fluorescence from the A-X $(1,1), \mathrm{A}-\mathrm{X}(0,0)$, and $\mathrm{B}-\mathrm{X}(0,1)$ bands was detected in the $420 \mathrm{~nm}$ to $440 \mathrm{~nm}$ range. This method gives a relatively high fluorescence yield and large separation between the excitation and fluorescence wavelengths which allows for sufficient filtering of the excitation beam. A diagram of the PLIF system arrangement is shown in Fig. 4. The second harmonic of an Nd:YAG laser (Spectra-Physics LAB-150) was used to pump a dye laser (Sirah CSTR-D-24). A mixture of Rhodamine 610 and Rhodamine 640 dyes were used to obtain a beam near $616 \mathrm{~nm}$. This beam was mixed with the $1064 \mathrm{~nm}$ beam from the Nd:YAG laser using a KD*P mixing crystal. The resulting $390.30 \mathrm{~nm}$ beam was separated from the $616 \mathrm{~nm}$ and $1064 \mathrm{~nm}$ beams using a Pelin-Broca prism. The $390.30 \mathrm{~nm}$ beam was expanded using a 3:1 Galilean telescope and a concave cylindrical lens with a focal length of $-100 \mathrm{~mm}$. The central $\sim 40 \%$ of the beam was then focused into a sheet using a convex spherical lens with a focal length of $1000 \mathrm{~mm}$. The resulting sheet had a height of $60 \mathrm{~mm}$ and a thickness of $300 \mu \mathrm{m}\left(1 / e^{2}\right.$ width $)$ in the region of interest.

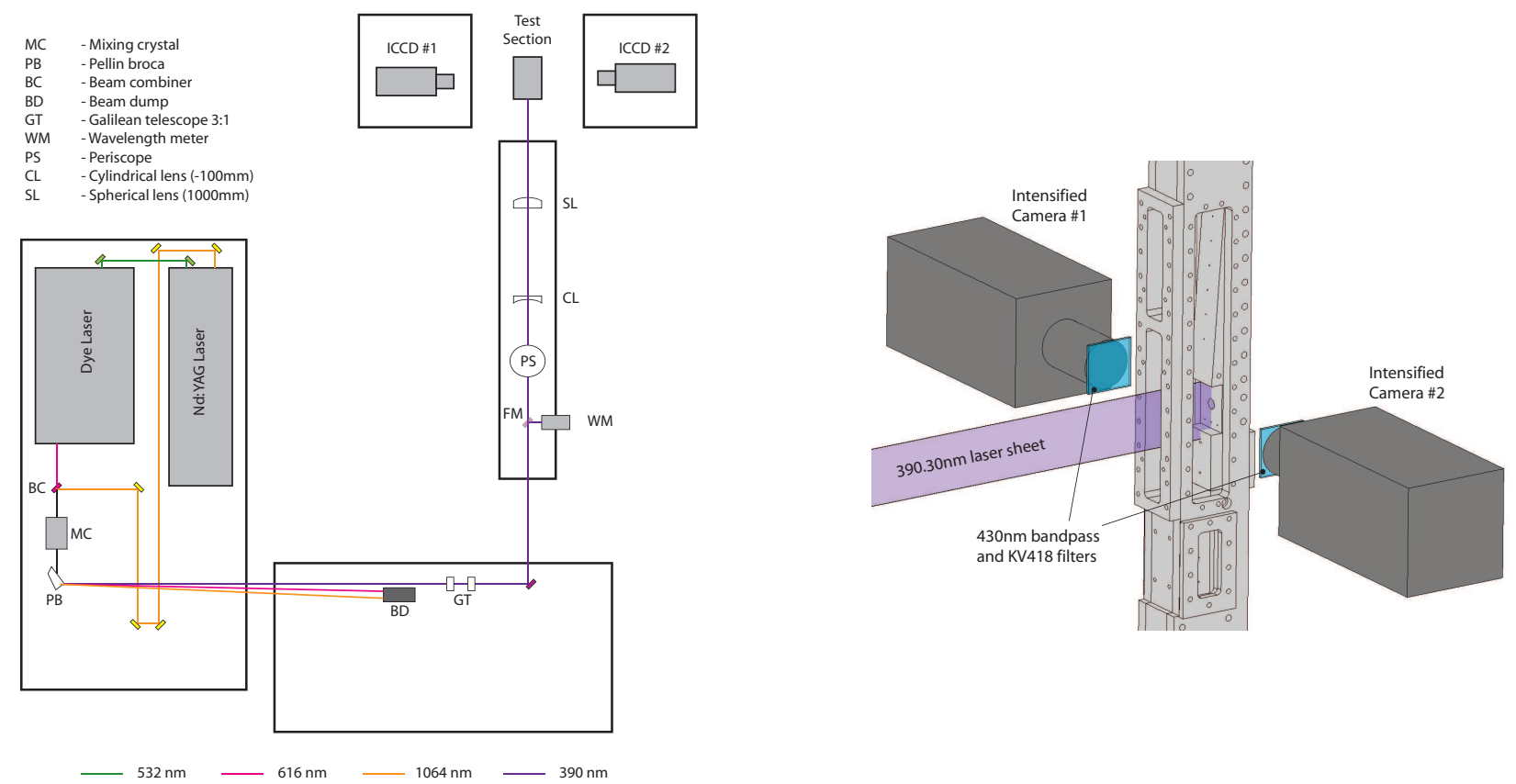

Figure 4. CH-PLIF system arrangement.

The energy in the sheet was $8 \mathrm{~mJ} /$ pulse. The $9 \mathrm{~ns}$ duration of each pulse and $1 \mathrm{~cm}^{-1}$ linewidth of the beam gave a spectral intensity of approximately $5 \times 10^{6}\left(\mathrm{~W} / \mathrm{cm}^{2}\right) / \mathrm{cm}^{-1}$. This is five time greater than the spectral intensity needed for saturation. ${ }^{22}$ Saturation is therefore expected in the center of sheet width and the center of the pulse, but not in the edges of time or space. Due to this partial saturation, the PLIF signal is assumed to have a nonlinear response to variations in intensity across the height the laser sheet. The 
edges of the $60 \mathrm{~mm}$ high laser sheet had approximately half the power as the middle of the sheet. Because the focus of this investigation is the structure and location of the reaction zone, quantitative interpretation of the signal was not necessary and no sheet correction was made.

A 16-bit Andor Istar intensified CCD camera was used to collect the fluorescence. A bandpass interference filter with a $430 \mathrm{~nm}$ center wavelength and 10nm full-width at half-maximum was used to block scattering from the pump beam and flame luminosity. A KV418 filter was also used to further block scattering from the pump beam. A f/2.0, $50 \mathrm{~mm}$ Nikkor lens with a $12 \mathrm{~mm}$ extension tube was used to obtain the desired field of view size. The CCD was binned $3 \times 3$ and cropped to obtain an array of super pixels $341 \times 137$ or $341 \times 214$ with each superpixel covering $220 \mu \mathrm{m}$. The smaller array could be acquired at $5 \mathrm{~Hz}$ and the larger array at $3.33 \mathrm{~Hz}$. The size and locations of the fields of view for each case were chosen to maximize the number of images acquired in the region of interest and are shown in Fig. 5. All images were acquired along the test section centerline. The $x$ dimension of each field of view was set by the $60 \mathrm{~mm}$ height of the laser sheet while the $y$ dimension was set by the pixel array cropping.

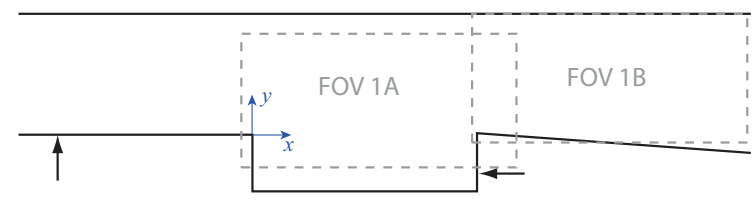

(a) Case 1 PLIF fields of view

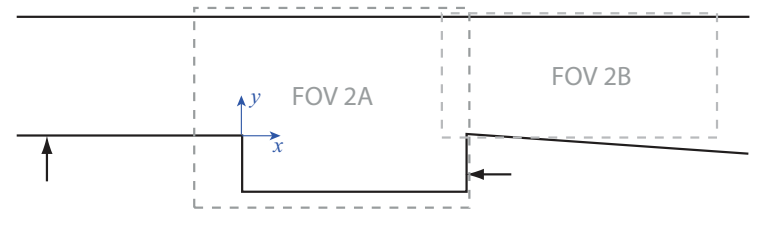

(b) Case 2 PLIF fields of view..

Figure 5. Upstream and downstream PLIF fields of view.

\section{Flame Luminosity Subtraction}

The timing of the camera and laser was controlled with a DG535 pulse generator and was optimized in a Bunsen flame before being applied to the scramjet combustor. The minimum camera gate width that did not suppress the PLIF signal in the bunsen flame was found to be $15 \mathrm{~ns}$. The resulting PLIF signal was 1000-3000 counts above the mean background. The background noise was randomly distributed with a standard deviation of approximately 200 counts giving an acceptable signal to noise ratio. When this system was applied to the scramjet combustor however, the primary component of the noise became the flame luminosity which caused a signal of 3000+ counts above the mean background. The PLIF signal ranged up to 10000 counts above the background, but in many areas it was significantly lower and could not be distinguished from the flame luminosity signal. Figure 6(a) shows an example flame luminosity image acquired with no laser sheet for case 2 conditions. Figure 6(b) was acquired $50 \mathrm{~ns}$ later with a $390.50 \mathrm{~nm}$ laser sheet to show the effect of broadband fluorescence from polycyclic aromatic hydrocarbons (PAH) is relatively minor. The high flame luminosity signal was a somewhat surprising result given the minimal PAH in the flame and the use of a $15 \mathrm{~ns}$ camera gate with a bandpass interference filter. Increasing the camera gate time to $50 \mathrm{~ns}$ resulted in a proportional increase in the flame luminosity signal. This verified that the signal observed was indeed acquired during the short gate open time, and was not due to leakage through the closed gate during the hundreds of milliseconds between frames.

To help separate the PLIF signal from the flame luminosity signal, a second, identical intensified camera, lens, and filter stack was set up to view the test section from the opposite side as the first camera (ICCD 1) as shown in Fig. 4. This camera, ICCD 2, was also gated to $15 \mathrm{~ns}$ and was triggered 50 ns before the arrival of the laser sheet and thus recorded only flame luminosity. Ideally the flame luminosity signal from ICCD 2 could be subtracted from the images containing the flame luminosity and PLIF signal from ICCD 1 leaving only the PLIF signal. In reality though, the two cameras can only be mapped to one another on a single plane. The flame luminosity signal is a line of sight integrated property which suffers from perspective error over the width of the test section when mapped to the focal plane. Thus this correction reduces, but does not eliminate, the flame luminosity signal.

The final image processing consisted of the following steps. First the mean background was subtracted and a whitefield correction was applied to both cameras in the method detailed by Clemens. ${ }^{23}$ The mean background was obtained for each run by continuing to take data with each camera for 4 seconds after the 


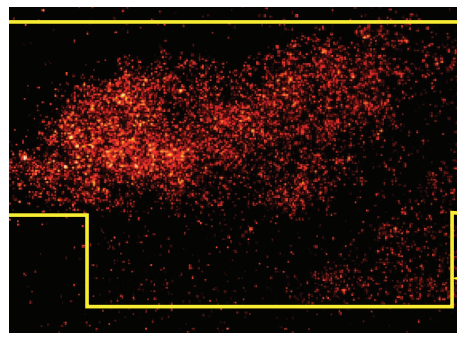

(a) ICCD 2, no laser sheet.

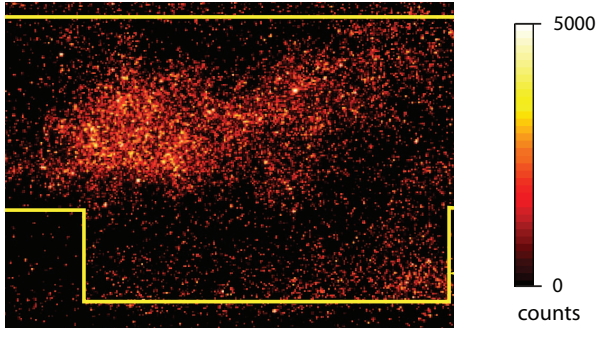

(b) ICCD 1, $390.50 \mathrm{~nm}$ laser sheet.

Figure 6. Example flame luminosity images with and without the 390.50 nm laser sheet for case 2 conditions, FOV 2A. ICCD 1 and ICCD 2 images acquired $50 \mathrm{~ns}$ apart. Air flow is from left to right.

main fuel was turned off. The two cameras were then mapped to the same coordinates on the focal plane using DaVis software and images of a clear target. Next the images from each camera were filtered with a 2 $\times 2$ superpixel moving average filter. This relatively minimal filter helped improve the luminosity correction by smoothing out the perspective error between the two cameras. Finally the processed ICCD 2 images were subtracted from the processed ICCD 1 images leaving the luminosity corrected PLIF images.

The noise level of the luminosity corrected PLIF images was determined by tuning the laser sheet to $390.50 \mathrm{~nm}$ and taking images of the combustor in operation with both cameras. The final processed images in this case represent the noise level. Using a $390.50 \mathrm{~nm}$ laser sheet in the ICCD 1 images allowed the effect of any PAH or other particles emitting broadband fluorescence to be accounted for in the noise images. Very little signal was found above 2000 counts for these filtered, luminosity corrected images. The few pixels above this value tended to be randomly distributed with no structure. Therefore 2000 counts was set to be the lower threshold for the CH images shown in Sec. [II. Figure 7 shows an example of the noise reduction obtained by the image processing for one of the brightest images obtained with the 390.50nm laser sheet. Figure 8$]$ shows this image processing applied to an example CH-PLIF image (390.30 nm laser sheet). Both Figs. 7 and 8 are shown on the same scale as the processed PLIF images in Sec. III.

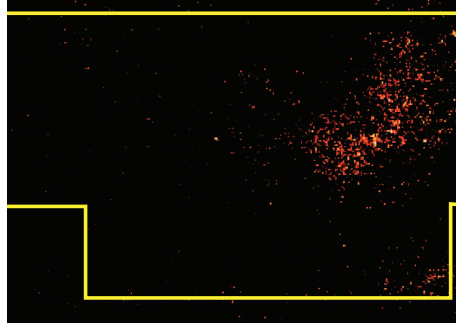

(a) No luminosity subtraction.

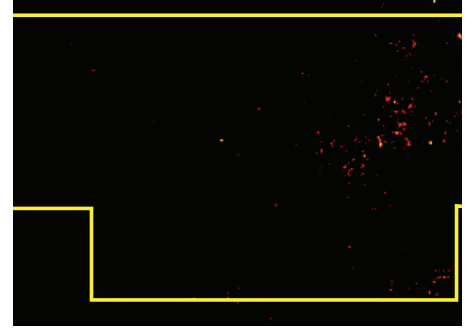

(b) With luminosity subtraction, no filtering.

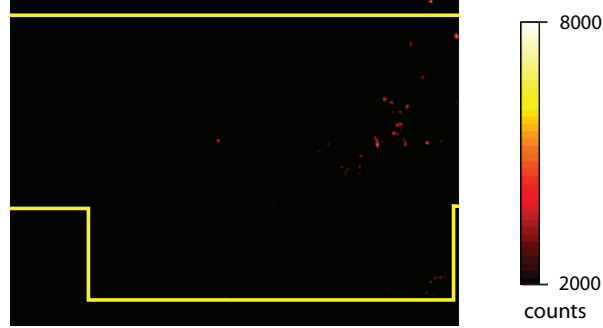

(c) With filtering and luminosity subtraction.

Figure 7. Example high signal image with $390.50 \mathrm{~nm}$ laser sheet showing the effects of luminosity subtraction. Case 2 conditions, FOV 2A. Air flow is from left to right.

\section{Results and Discussion}

\section{A. Case 1 instantaneous $\mathrm{CH}$ images}

Figure 9 shows some example instantaneous CH-PLIF images for case 1 (cavity stabilized) flow conditions. Images from regions FOV $1 \mathrm{~A}$ and FOV $1 \mathrm{~B}$ were acquired at different times and shown together for convenience. Most of the instantaneous images showed that the $\mathrm{CH}$ is confined to relatively thin, nearly continuous layers as shown in Figs. 9(a-c). Thin continuous reaction layers are a indication that the combustion is likely occurring as a flame, and not due to auto-ignition. The apparent thickness of the $\mathrm{CH}$ layers varies from 


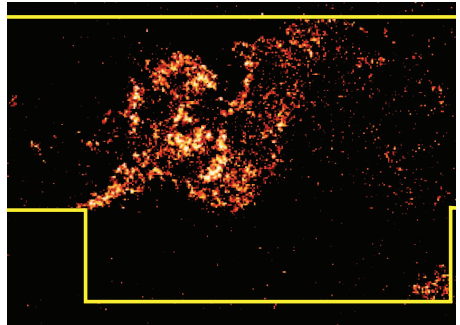

(a) No luminosity subtraction.

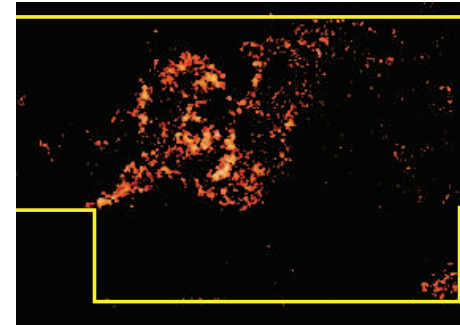

(b) With luminosity subtraction, no filtering.

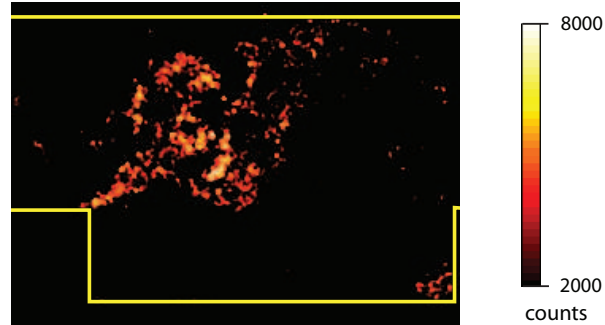

(c) With filtering and luminosity subtraction.

Figure 8. Example instantaneous PLIF image (390.30 $\mathrm{nm}$ laser sheet) showing the effects of luminosity subtraction. Case 2 conditions, FOV 2A. Air flow is from left to right.

approximately 2 to 15 superpixels, or 0.4 to $3.3 \mathrm{~mm}$. The regions which appear thickened may actually be due to tightly wrinkled thin layers that cannot be distinguished due to spatial resolution limitations caused by sheet thickness, pixel size, and the filtering process.

The leading edge of the $\mathrm{CH}$ layer is usually located in the upstream part of the cavity shear layer and does not move significantly. This location allows for relatively steady flamefront stabilization. A similar conclusion was reached previously from the flame luminosity images. ${ }^{13}$ As the flame spreads out into the main flow, the reaction layers generally became more wrinkled, thicker, and more discontinuous. In some images, the $\mathrm{CH}$ was located in several isolated clusters, as opposed to thin, continuous layers. Figure 9(d) shows an example of these structures which were more commonly observed in the downstream view (FOV 1B) than the upstream view (FOV 1A). It is believed that these clusters are located in large turbulent structures which are convecting downstream.

\section{B. Case 2 instantaneous $\mathrm{CH}$ images}

Figure 10 shows some example instantaneous CH-PLIF images for case 2 (jet-wake stabilized) flow conditions. Images from FOV $2 \mathrm{~A}$ and FOV $2 \mathrm{~B}$ were acquired at different times and shown together for convenience. The structure of the reaction zone is not as clear for case 2 and for case 1 . The base of the reaction zone is generally located upstream of the cavity leading edge but it varies significantly in shape and location between different images. In some cases, such as Figs. 10(a,b), the CH signal looks similar to that for a lifted jet flame, ${ }^{24}$ albeit highly shredded. In both these images the reaction zone begins with a region of high CH signal along what appears to be the upper and lower edges of the fuel jet. Behind these locations are what appear to be highly shredded reaction layers. In other cases however, no such structures resembling the upper and lower boundaries of the fuel jet can be seen. In some cases the $\mathrm{CH}$ was found in relatively concentrated and isolated clusters such as shown in $10(\mathrm{~d})$.

\section{Average $\mathrm{CH}$ images}

Figure 11 shows the ensemble average of the CH-PLIF signal for case 1 and case 2 . In order to minimize the contribution the of flame luminosity, only pixels with greater than 1000 counts in each instantaneous image were counted towards the average. The shape of the average $\mathrm{CH}$ distribution for each case looks quite similar to the average flame luminosity images shown in Fig. 1. The $\mathrm{CH}$ distribution provides assurance that the region being viewed is actually the reaction zone, and not hot products convected downstream. For both cases it can be seen that the end of the reaction zone has not been reached in the regions imaged. Future work will examine the $\mathrm{CH}$ further downstream to determine the length of the reaction zone. Furthermore, the $\mathrm{CH}$ signal is from a single plane rather than being line of sight integrated. In the future, planes off the centerline of the combustor will be imaged to determine the three dimensional structure of the reaction zone. 
counts
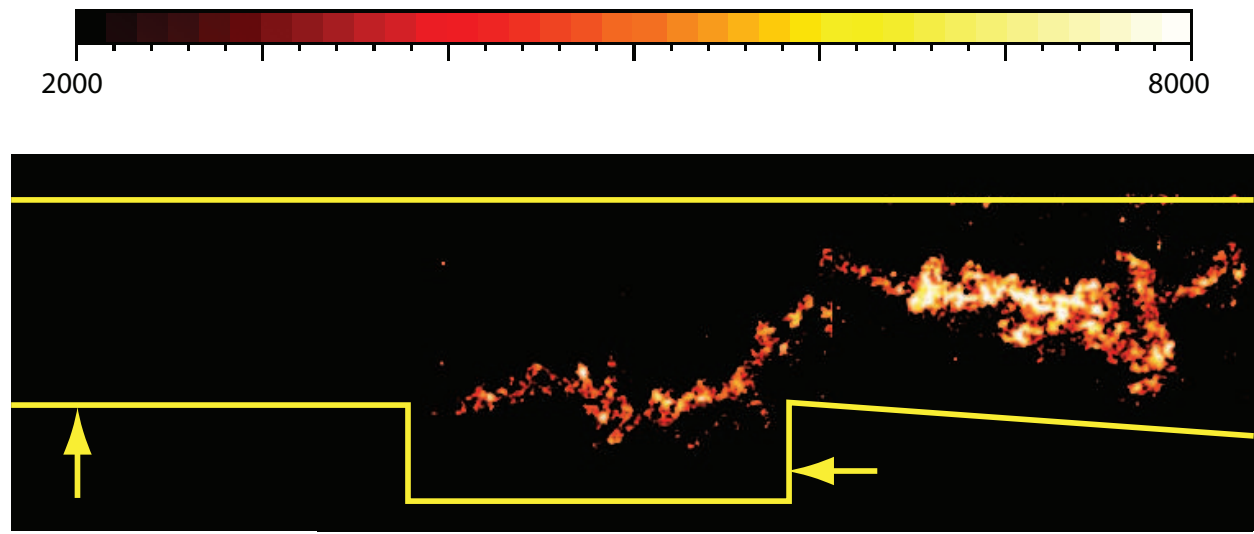

(a)

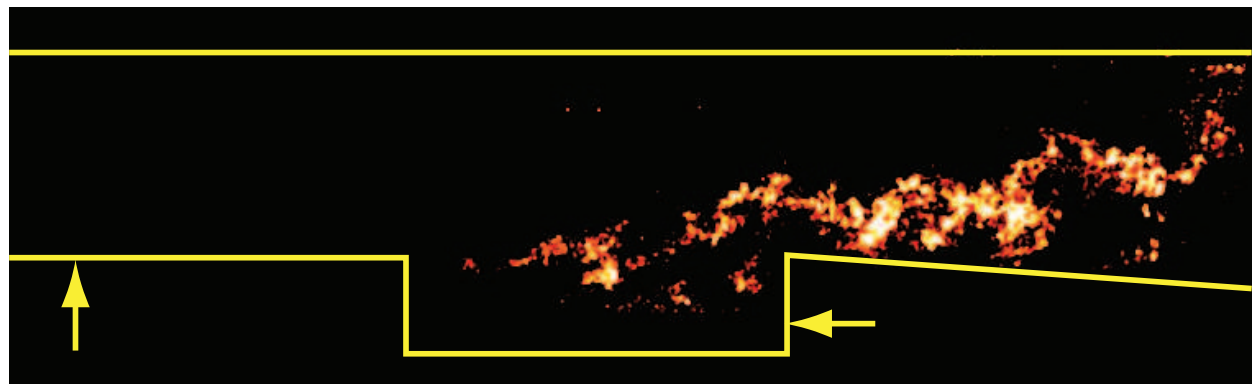

(b)

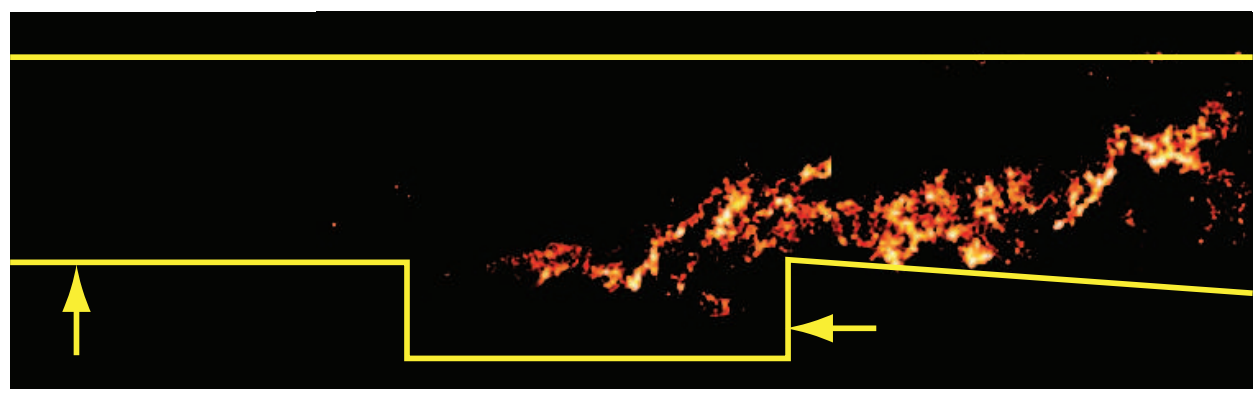

(c)

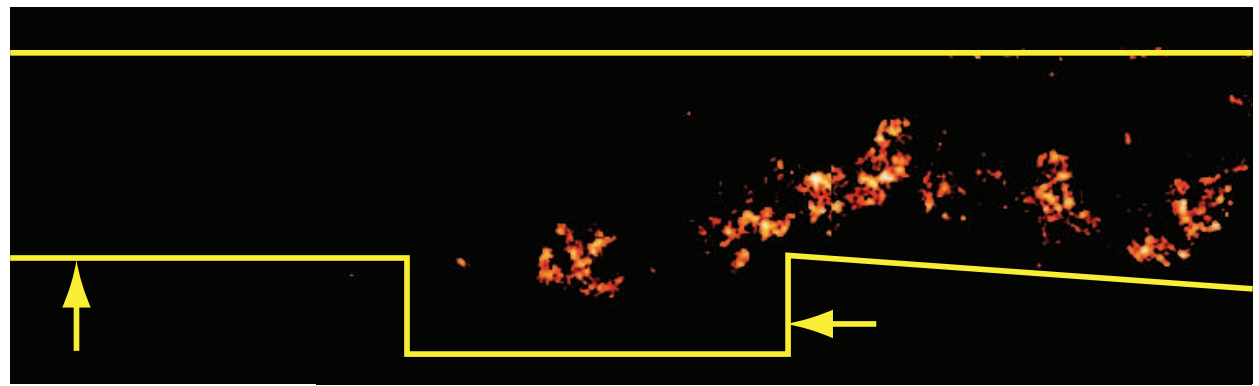

(d)

Figure 9. Case 1 example instantaneous CH PLIF images. Images from two fields of view were acquired at different times and stitched together. Air flow is from left to right. 
counts
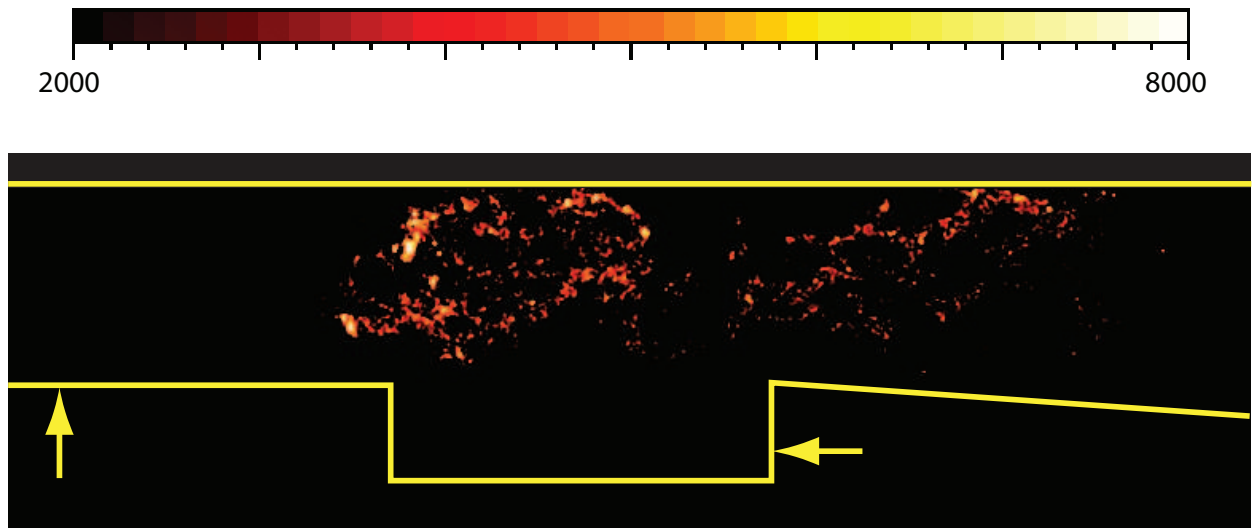

(a)

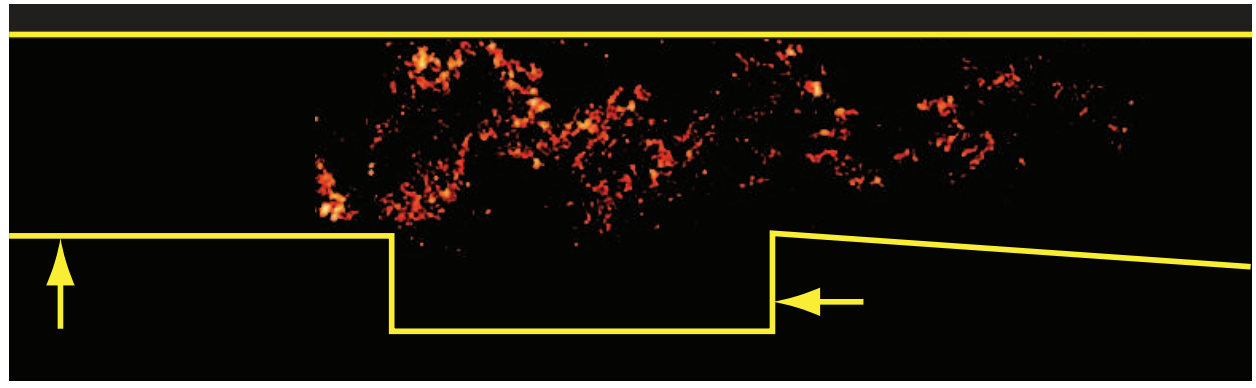

(b)

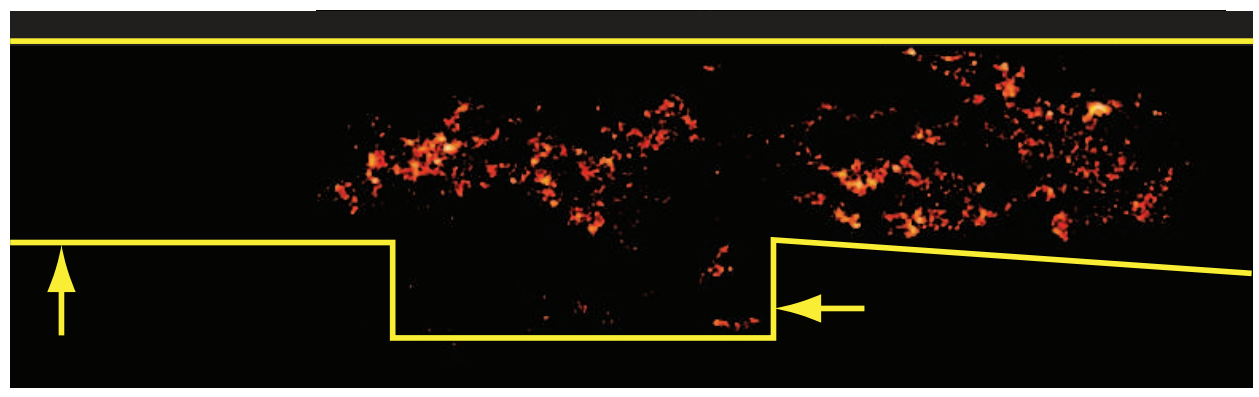

(c)

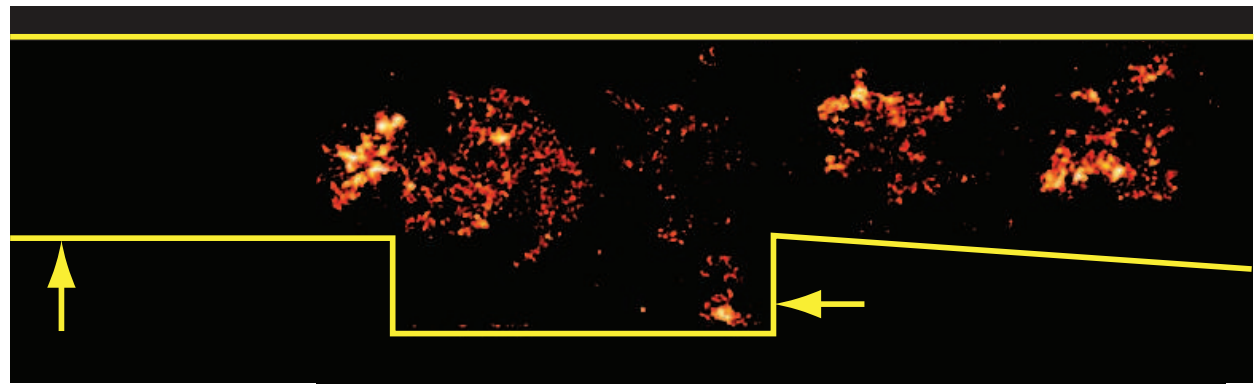

(d)

Figure 10. Case 2 example instantaneous CH PLIF images. Images from two fields of view were acquired at different times and stitched together. Air flow is from left to right. 


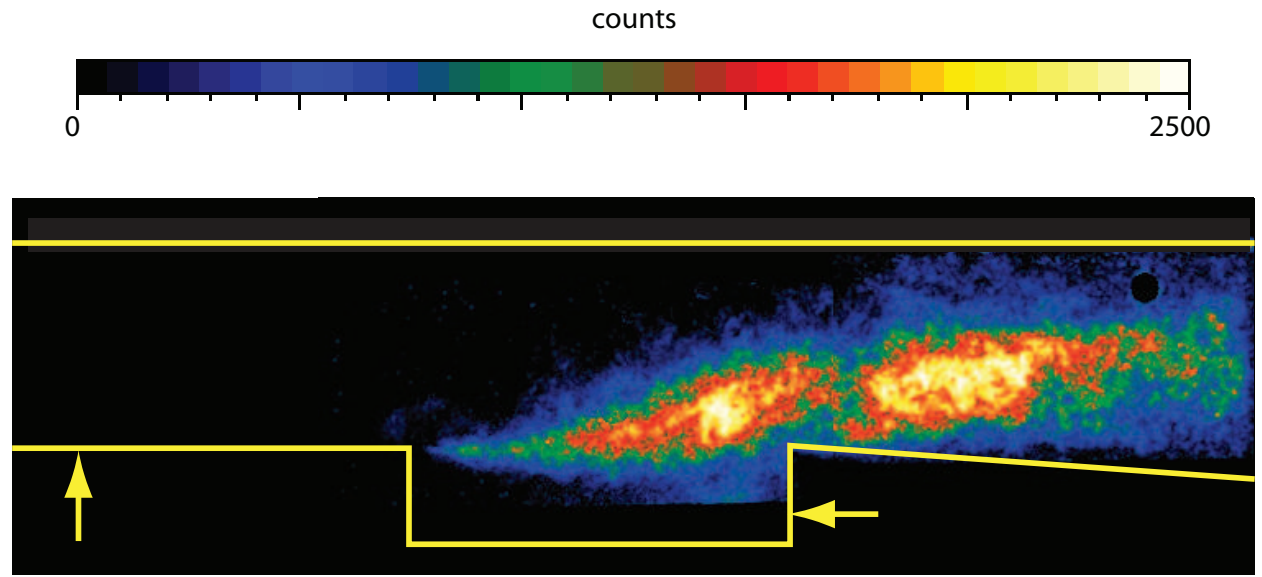

(a) Case 1, cavity stabilized flame. Average of 40 images from FOV 1A and 35 images from FOV $1 \mathrm{~B}$.

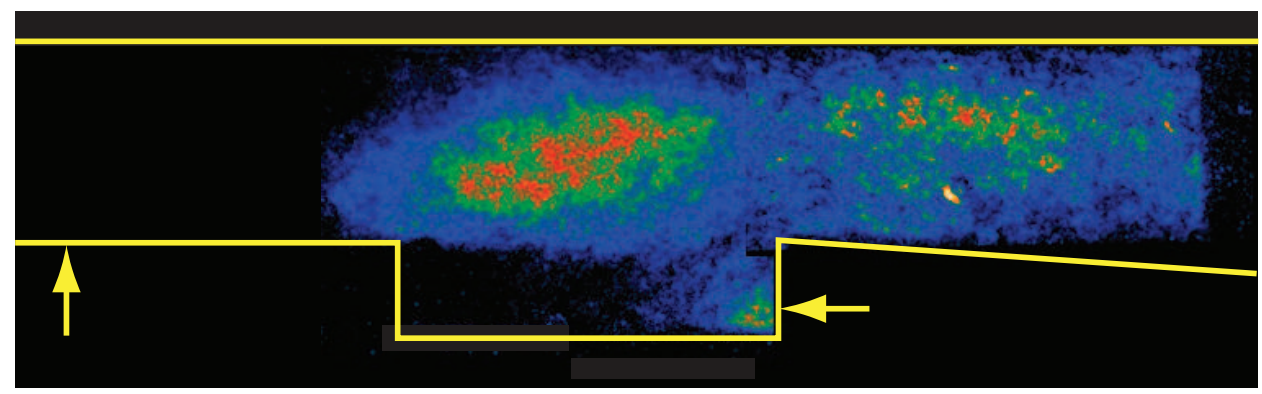

(b) Case 2, jet-wake stabilized flame. Average of 80 images from FOV $2 \mathrm{~A}$ and 25 images from FOV 2B.

Figure 11. Ensemble averaged CH-PLIF. Air flow is from left to right. 


\section{Conclusions and Future Work}

The reaction zone in a dual-mode scramjet combustor has been imaged using CH-PLIF for the first time. The flame luminosity caused significant interference with the PLIF signal over the collection wavelengths of 420-440 nm. A two camera technique was used to reduce this flame luminosity interference. For both conditions studied, the instantaneous $\mathrm{CH}$ reaction zone is confined to relatively thin $(<3.3 \mathrm{~mm})$ layers, and is not well distributed. For case 1 (cavity stabilized combustion) the flame base is located in the upstream part of the cavity shear layer and is mostly steady. The flame spreads into the main flow as continuous or shredded reaction layers. For case 2 (jet-wake stabilized combustion) the reaction zone is generally highly shredded and continuous layers are not observed. The flame base is located upstream of the cavity in the wake of the fuel injection jet and varies significantly from image to image. The ensemble averaged CH-PLIF images for both cases showed the reaction zone to be distributed in space and similar in appearance to the average flame luminosity images. In the future the CH-PLIF diagnostics will be used to image locations further downstream in the combustor and off the combustor centerline. This will help to define the three dimensional structure of the reaction zone and to locate the end of the flame.

\section{References}

${ }^{1}$ Ben-Yakar, A. and Hanson, R. K., "Cavity flame-holders for ignition and flame stabilization in scramjets: an overview," Journal of Propuslion and Power, Vol. 17, No. 4, 2001, pp. 869-877.

${ }^{2}$ Mathur, T., Gruber, M., Jackson, K., Donbar, J., Donaldson, W., Jackson, T., and Billig, F., "Supersonic combustion experiments with a cavity based fuel injector," Journal of Propuslion and Power, Vol. 17, No. 6, 2001, pp. 1305-1312.

${ }^{3}$ Gruber, M. R., Donbar, J. M., Carter, C. D., and Hsu, K.-Y., "Mixing and combustion studies using cavity-based flameholders in a supersonic flow," Journal of Propuslion and Power, Vol. 20, No. 5, 2004, pp. 769-778.

${ }^{4} \mathrm{Yu}, \mathrm{K} . \mathrm{H}$., Wilson, K. J., and Schadow, K. C., "Effect of flame-holding cavities on supersonic-combustion performance," Journal of Propuslion and Power, Vol. 17, No. 6, 2001, pp. 1287-1295.

${ }^{5}$ Donbar, J. M., Gruber, M. R., Jackson, T. A., Carter, C. D., and Mathur, T., "OH planar laser-induced fluorescence imaging in a hydrocarbon-fueled scramjet combustor," Proceedings of the Combustion Institute, Vol. 28, 2000, pp. 679-687.

${ }^{6} \mathrm{Yu}, \mathrm{G}$., Li, J., Zhao, J., Yue, L., Chang, X., and Sung, C.-J., "An experimental study of kerosene combustion in a supersonic model combustor using effervescent atomization," Proceedings of the Combustion Institute, Vol. 30, 2005, pp. 28592866.

${ }^{7}$ Mitani, T. and Izumikawa, M., "Criteria for flame holding in H2-fueled scramjet engines," Proceedings of the Combustion Institute, Vol. 28, 2000, pp. 689-695.

${ }^{8}$ Baurle, R. A. and Eklund, D. R., "Analysis of dual-mode hydrocarbon scramjet operation at mach 4-6.5," Journal of Propuslion and Power, Vol. 18, No. 5, 2002, pp. 990-1002.

${ }^{9}$ Neely, A. J., Stotz, I., O’Byrne, S., Boyce, R. R., Mudford, N. R., and Houwing, A. F. P., "Flow studies on a hydrogen-fueled cavity flame-holder scramjet," 13th International Space Planes and Hypersonics Systems and Technologies, 2005, pp. AIAA 2005-3358.

${ }^{10}$ Choi, J.-Y., Ma, F., and Yang, V., "Combustion oscillations in a scramjet engine combustor with transverse fuel injection," Proceedings of the Combustion Institute, Vol. 30, 2005, pp. 2851-2858.

${ }^{11}$ Lin, K.-C., Jackson, K., Behdadnia, R., Jackson, T. A., Ma, F., Li, J., and Yang, V., "Acoustic Characterization of an Ethylene-Fueled Scramjet Combustor with a Recessed Cavity Flameholder," Joint Propulsion Conference and Exhibit, 2007, pp. AIAA 2007-5382.

${ }^{12}$ Lin, K.-C., Tam, C.-J., Boxx, I., Carter, C., Jackson, K., and Lindsey, M., "Flame characteristics and fuel entrainment inside a cavity flame holder in a scramjet combustor," Joint Propulsion Conference and Exhibit, 2007, pp. AIAA $2007-5381$.

${ }^{13}$ Micka, D. J. and Driscoll, J. F., "Combustion Characteristics of a Dual-Mode Scramjet Combustor with Cavity Flameholder," To appear in Proceedings of the Combustion Institute, Vol. 32, 2009.

${ }^{14}$ Porter, R. P., Clark, A. H., Kaskan, W. E., and Browne, W. E., "A study of hydrocarbon flames," Proceedings of the Combustion Institute, Vol. 11, 1967, pp. 907-917.

${ }^{15}$ Parker, T. E., Allen, M. G., Foutter, R. R., Reinecke, W. G., Legner, H. H., Davis, S. J., and Rawlins, W. T., "An experimental study of supersonic H2-air combustion in a shock tunnel flow facility," Proceedings of the Combustion Institute, Vol. 24, 1992, pp. 1613-1620.

${ }^{16}$ Ben-Yakar, A. and Hanson, R. K., "Experimental investigation of flame-holding capability of hydrogen transverse jet in supersonic cross-flow," Proceedings of the Combustion Institute, Vol. 27, 1998, pp. 2173-2180.

${ }^{17}$ OByrne, S., Stotz, I., Neely, A. J., Boyce, R. R., Mudford, N. R., and Houwing, A. F. P., "OH PLIF imaging of supersonic combustion using cavity injection," 13th International Space Planes and Hypersonics Systems and Technologies, 2005, pp. AIAA 2005-3357.

${ }^{18}$ Rasmussen, C. C., An experimental study of flame stability in a directly-fueled wall cavity with a a supersonic free stream, Ph.D. thesis, University of Michigan, 2006.

${ }^{19}$ Curran, E. T., Heiser, W. H., and Pratt, D. T., "Fluid phenomena in scramjet combustion systems," Annual Review of Fluid Mechanics, Vol. 28, 1996, pp. 323-360.

${ }^{20}$ Garland, N. L. and Crosley, D. R., "Energy transfer processes in CH a2-delta and b2-sigma in an atmospheric pressure flame," Applied Optics, Vol. 24, No. 23, 1985, pp. 4229-4237. 
${ }^{21}$ Carter, C. D., Donbar, J. M., and Driscoll, J. F., "Simultaneous CH planar laser-induced fluorescence and particle imagine velocimetry in turbulent nonpremixed flames," Applied Physics B, Vol. 66, 1998, pp. 129-132.

${ }^{22}$ Sutton, J. A. and Driscoll, J. F., "Optimization of CH fluorescence diagnostics in flames: range of applicability and improvements with hydrogen addition," Applied Optics, Vol. 42, No. 15, 2003, pp. 2819-2828.

${ }^{23}$ Clemens, N. T., Encyclopedia of Imaging Science and Technology, chap. Flow imaging, John Wiley and Sons, 2002, pp. $390-419$.

${ }^{24}$ Watson, K. A., Lyons, K. M., Carter, C. D., and Donbar, J. M., "Simultaneous two-shot ch planar laser-induced fluorescence and particle image velocimetry measurements in lifted ch4/air diffusion flames," Proceedings of the Combustion Institute, Vol. 29, 2002, pp. 1905-1912. 